\title{
Inclusive Component of Modern Higher Education, Its Socio- Cultural Role and Development Prospects
}

\author{
NATALIIA KRECHKO*1, OLENA SKOPTSOVA ${ }^{2}$, LARYSA OSTAPENKO ${ }^{3}$, \\ ZHANNA ZAKRASNIANA ${ }^{4}$, IHOR TYLYK ${ }^{5}$ \\ 1,2,3,4,5 Department of Musical Arts, KYIV NATIONAL UNIVERSITY OF CULTURE AND ARTS, UKRAINE. \\ *E-mail: nat.krechko@tutanota.com
}

\begin{abstract}
The article is devoted to defining new approaches to understanding the essence of modern inclusive higher education. In order to establish who needs special educational conditions today, a survey of students of the 1st, 3rd and 5th study years was carried out. It showed that most students today need help with communication and integration. Correlation analysis based on the data obtained from the survey gives every opportunity to assert that the links between the questions of it for certain groups of students (target groups of 17-18 years old and 19-20 years old) are pretty strong. Based on this, it was concluded that communication problems in groups of students decrease over time, but over a reasonably long period. Therefore, during the first years of university education, there is a necessity to talk not about inclusion but integration.

Special attention was devoted to highlighting the problems of modern inclusive higher education, its sociocultural aspect and its role in forming society in the future. In addition, instruments were proposed with the help of which it is possible to achieve the fundamental goals of inclusive education.
\end{abstract}

Keywords: inclusive education, inclusive higher education, integration, pedagogy

JEL Classification: 124, 126, A13, M14 


\section{Introduction.}

Modern education faces a lot of quite essential issues as well as real challenges. Only ten years ago, material provision, classroom funds and sufficient computerization were almost the most significant problems to be solved by the administration of universities and state. Now we see that the development of modern, qualified, skilled, polite personalities undoubtedly gradually reaches the top [1-2].

A reasonable question: development of personalities and practical training of future professionals always were the core goals of higher education, so what is the problem? Nowadays, students are other; they are citizens of the world, their thoughts, dreams, inspirations, and internal characteristics are developing in step with the times.

However, still, it is only part of the problem. The critical point is that modern technological, economic, cultural, and social development is speeding [3], which increases the temp of students' change. Thus, higher education must maintain the same pace to stay actual, essential and demandable [4-5]. Moreover, that is the problem.

All these pointed questions for modern higher education have circled the necessity to consider all kinds of needs and wishes of potential (or further) students - inclusive component.

In order to highlight the features of inclusive higher education, a lot of fundamental publications were made. At the same time, in our opinion, inclusive higher education is something else. Inclusive components nowadays (and especially at the current moment, when much educational process in thousands of universities is organized online) must be focused on all and each student without any exceptions, which brings additional tasks for the dean's offices and teaching staff.

Based on this statement, modern teachers (lecturers) must have developed skills in the understanding of personalities, their needs and possibilities, to identify their strength, to be involved even in personal life (if they require it), in the end - be a real psychologist. That is why, with the high rate of probability, we can say that future universities will be more than facilities to learn, to develop, to communicate, but also centers to ensure the personal growth for every of students regardless of their physical, intellectual, social needs. It opens an additional field to discuss modernizing the basics of higher education - the new approaches to train future teaching staff.

Another critical problem is identifying a modern content of inclusive higher education, deciding on whom it must be oriented, and what instruments it must be achieved.

It is generally accepted that inclusive education is mainly aimed at people with special needs [6]. Thus, there is some division between those who have specific special needs and those who do not. We believe this is not entirely correct and that inclusive education today should be focused on every student.

\section{The purpose of the article.}

This article is devoted to studying possible ways to build a bridge between the inclusiveness of students, the development of personality in society (which gives its socio-cultural aspect), and the search for directions for the future development of human resources in higher education.

\section{Presentation of the primary material.}

According to the general approach, inclusive higher education is the form of organizing educational process, which considers the interests of students with special educational needs and their socialization and integration into society on the most careful and suitable basis [7-8].

By the psychological ladder in education (general educational), inclusion is the last step to involve the pupils with special educational needs; the other ones are:

- $\quad 1$ st step, widening participation, which means enlarged access to education of wider circles of pupils; 
- $\quad$ 2nd step, mainstreaming, which is temporary joint education of pupils with special needs and their peers as well as providing of different outclass events (likewise: celebrations, leisure, other);

- $\quad 3 r d$ step, integration, which is based on permanent, unlimited joint education of pupils with special needs and peers. However, this step does not mean that educational facilities must be mandatory rebuild according to the necessities of pupils with special needs;

- $\quad$ 4th step, inclusion itself, which means serious reforming of education and rebuilding of all (at least, the majority) of educational facilities with orientation on pupils with special needs to create for them to have a comfortable and accessible educational environment for themselves and their peers.

There is a fundamental difference between inclusive education at secondary and higher (universities) schools. Suppose pupils at secondary schools have possibilities to joint growth from a child till teen ages, which determines their emotional and psychologic development and getting of knowledge and skills by them go in parallel than in universities. In that case, emotionally different students, students with different educational necessities fall into an environment in which they must rebuild communication bridges, the absence of which can reduce the effectiveness of the educational process and lead to all sorts of problems (for example, bullying), which in itself is unacceptable.

Based on this statement, we can conclude that inclusion education at schools and universities is quite different. Also, to better understand our opinion, it is essential to explain that we are not discussing the physical rebuilding of premises, making a purchase of special equipment. However, we are focusing on the personal communications of peers with different educational needs in a single society.

Through that, we are coming to another important question - how to understand who those students who have special needs are?

Figure 1. Questionnaire of the survey participant. This survey, due to quarantine limitations, was provided online Questionnaire of the survey participant

1. Specify yours age:

$17-18$

$19-20$

$21-22$<smiles>C1CCC1</smiles><smiles>C1CCC1</smiles><smiles>C1=CCC1</smiles>

2. Did you have any problems communicating with your classmates after admission?

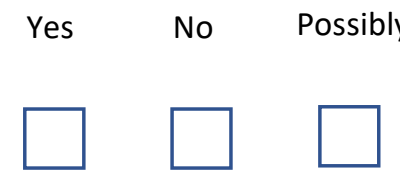

3. Do you still feel inconvenience in your group?

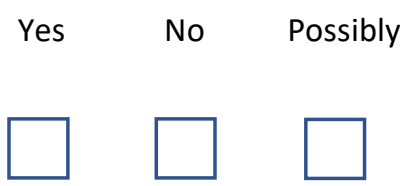

4. Is it related to the environment in the group?

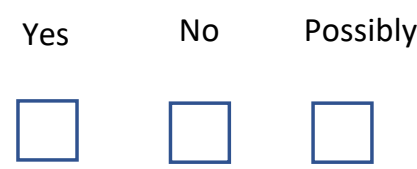

5. How do you mostly prefer to communicate with your classmates?

At the breaks

At the breaks and after classes

Using social networks (on smartphone or computer)

Prefer not to communicate with classmates 
For this purpose, we decided to organize a short anonymous volunteer questionary to identify students with special needs. These were mainly Kyiv National University of Culture and Arts students and students of partner universities in Ukraine. When designing such a questionary, we were not asking questions on social status, children's psychological traumas, or other kinds of questions that may confuse or offend the students (Figure 1). We chose the questions in such a way as to find out the communicative environment in the groups. In addition, we set ourselves the task of finding out if there is a connection between the special educational needs of students and problems in communication. Students were informed about the purposes of such a survey.

The interview was offered to one group of 1st, 3rd and 5th-year students. All students from these groups agreed to take part in it. After the organization of this survey, we have got the following results (Table 1 ).

As we can see from Table 1, each group, according to information from the dean's office, includes few students, which require specific educational needs. Indeed, such quantity is insignificant (1-2\% from total amount). However, if even one student in the group requires special educational needs, all facilities and teaching processes must be organized with taking into account this fact.

Table 1. Baseline parameters for future research (Designed by authors based on results obtained in the process of the survey)

\begin{tabular}{|c|c|c|c|}
\hline Age & 17-18 & $19-20$ & $21-22$ \\
\hline Quantity of students in the group & 19 & 20 & 15 \\
\hline Quantity of interviewed students & 19 & 20 & 15 \\
\hline Students with special educational needs from total amount* & 3 & 2 & 2 \\
\hline \multicolumn{4}{|l|}{ Questions: } \\
\hline \multicolumn{4}{|c|}{ 2. Did you have any problems communicating with your classmates after admission? } \\
\hline Yes & 13 & 10 & 11 \\
\hline No & 3 & 6 & 4 \\
\hline Possibly & 3 & 4 & 1 \\
\hline \multicolumn{4}{|l|}{ 3. Do you still feel inconvenience in your group? } \\
\hline Yes & 10 & 7 & 5 \\
\hline No & 3 & 10 & 5 \\
\hline Possibly & 6 & 3 & 1 \\
\hline \multicolumn{4}{|l|}{ 4. Is it related to the environment in the group? } \\
\hline Yes & 12 & 11 & 3 \\
\hline No & 3 & 5 & 8 \\
\hline Possibly & 4 & 4 & 4 \\
\hline \multicolumn{4}{|c|}{ 5. How do you mostly prefer to communicate with your classmates? } \\
\hline At the breaks & 4 & 7 & 5 \\
\hline At the breaks and after classes & 2 & 3 & 2 \\
\hline Using social networks (on smartphone or computer) & 8 & 6 & 8 \\
\hline Prefer not to communicate with classmates & 5 & 4 & 0 \\
\hline
\end{tabular}

Except this, we suppose that it is necessary to give additional comments:

- It was not classical sociological research; the goal of the survey was to establish a connection between the problems of communication in common and the existence of special educational needs in particular.

- We believe that such survey cay be perceived as a representative, regardless of insignificant focus groups by its quantity. 
- Chosen student groups are ordinary: the majority of students were unfamiliar before admission.

- Moreover, students were born in different places and admitted from different schools, which is typical for the average group in university.

- Except for this, there was no specific logic by which the interviewed groups were chosen.

All these statements give us the right to assume that a somewhat similar environment exists in most student groups.

We have visualized obtained results (Figure 2).

Based on its results we obtained, it is possible to get quite curious information:

- 2nd question. The variant "Yes" gives information that at least half of students had a communicational problem with their peers during the first days/weeks of their education at university. In addition, from $7 \%$ to $20 \%$ of interviewed persons, which have chosen variant "Possible", had a feeling of inconvenience within their new society. Of course, this data is not dynamic - they fluctuate by the influence of different factors. That is why it is only a reflection of current opinions. However, it brightly describes an integration problem (not even inclusion) of first-year students from year to year.

Figure 2. The visualization of survey results

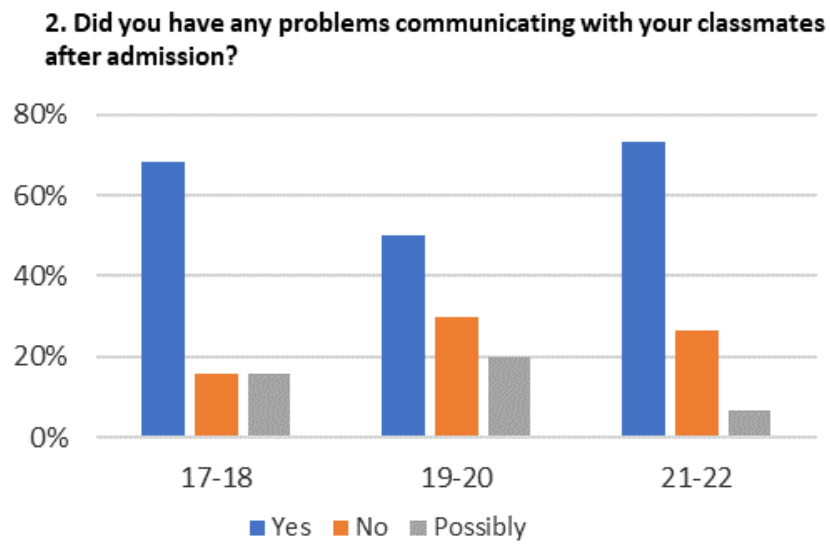

4. Is it related to the environment in the group?

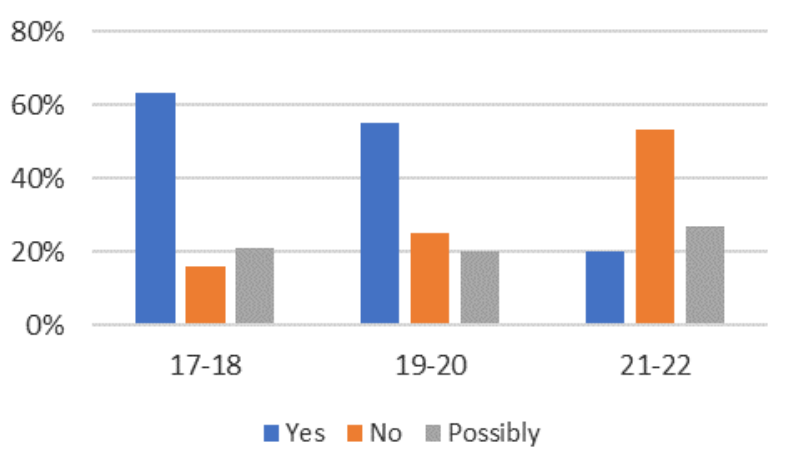

3. Do you still feel inconvenience in your group?

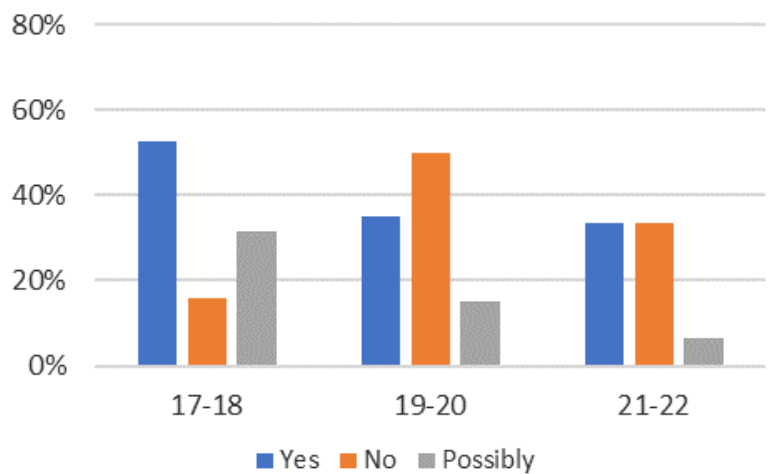

5. How do you mostly prefer to communicate with your classmates?

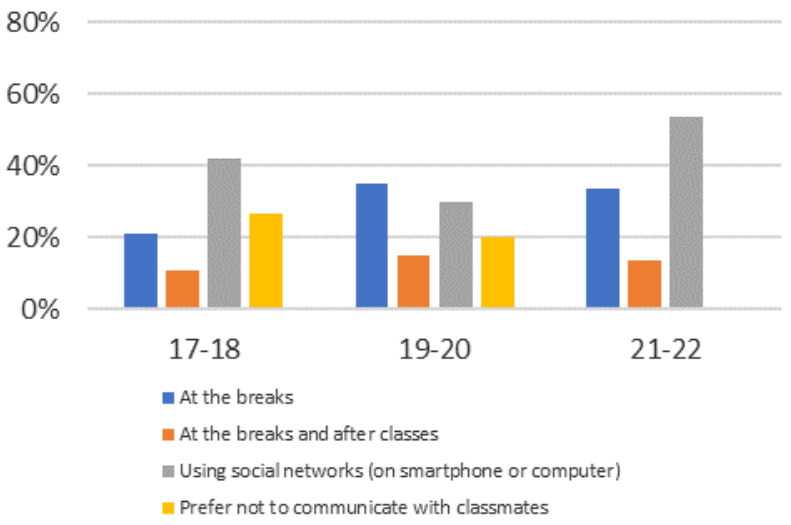

- $\quad 3$ rd question. This question is very similar to the previous one. However, here we can talk even about some dynamics. This indicator shows us a development pace of communication problems among the students with a simultaneous increase in their education in their group. We see that the respondents choose the variant "Yes" decreases from $53 \%$ to $30 \%$ for five years of study. It is accompanied by a 3-times increase of those students who choose variant "No", but only for the first 3-4 years. However, we can diagnose another kind of problem here. By paying additional attention to the 3-rd group (older students), it is evident that there is a repeated increase of those students who 
chose variant "No", which is a consequence of the redistribution of people who gave answers "Yes" and "Possible" earlier.

- 4th question helps us to explain the reasons for communicative problems among the students. Indeed, we cannot give a strict answer of what is the reason why there are such problems. At the same time, we can observe a connection between them and the communicational environment in student groups. Based on this statement, the communicational environment is influencing the psychological comfort and calm of most students within their society initially. After that, especially during the last year of education and graduation, communicative problems result from another factor.

- 5th question. While the formulation of this question, we wanted to find out the main communication methods between groupmates. Necessary caution: during the survey, we consciously suggested separate variants, "At the breaks" and "At the breaks and after classes". It was essential to understand whether they use some other time to communicate or the break-time only. During our further researches, we united these variants. Except this, it is possible to consider that first and last year students prefer to communicate mainly using different telecommunication systems. The amount of those students who prefer to communicate on social networks:

- for the first-year students $(42 \%)$ is higher than those who communicate during the breaks (32\% in amount);

- for the fifth-year students, the percentage of those who communicate by social networks is even higher $-54 \%$. In contrast, $46 \%$ prefer to communicate personally.

- For the students of the third year, the situation is more favorable - half of the students $(50 \%)$ would like to communicate with groupmates personally and only $30 \%$ by social networks.

Additionally, we have to pay attention to the actual psychological problem of some students $26 \%$ of young people (first-year students) and $20 \%$ of third-year students do not want to communicate with groupmates at all.

Extremely important to underline that the quantity of students who have a communicational problem is incomparably higher than the number of students who have officially confirmed special educational needs.

We supposed that it was enough to make all necessary conclusions for our research based on these inferences. However, we decided to go further and provide the correlation analysis of the results (Table 2 ).

When calculating these data, we tried to look for connections between the received answers given for each question and each focus group separately. For this purpose, Pearson's Correlation Coefficient (linear correlation coefficient) was used [9]. The following formula calculates it:

$$
r_{x y}=\frac{\sum_{i=1}^{n}\left(x_{i}-\bar{x}\right)\left(y_{i}-\bar{y}\right)}{\sqrt{\sum_{i=1}^{n}\left(x_{i}-\bar{x}\right)^{2}} \sqrt{\sum_{i=1}^{n}\left(y_{i}-\bar{y}\right)^{2}}},
$$

where:

$\mathrm{n}$ - the size of the sample;

$x$ - first variable;

$y$ - second variable. 
Table 2. Correlation analysis of the results obtained for the corresponding quadrants (Calculated by authors based on data of Table 1)

\begin{tabular}{|c|c|c|c|c|c|c|c|c|c|c|c|c|c|}
\hline \multirow{2}{*}{\multicolumn{2}{|c|}{ Focus group }} & \multirow{2}{*}{\multicolumn{4}{|c|}{$17-18(\mathrm{~A})$}} & \multirow{2}{*}{\multicolumn{4}{|c|}{$19-20(B)$}} & \multirow{2}{*}{\multicolumn{4}{|c|}{$21-22(C)$}} \\
\hline & & & & & & & & & & & & & \\
\hline (code) & Questions & 2 & 3 & 4 & 5 & 2 & 3 & 4 & 5 & 2 & 3 & 4 & 5 \\
\hline \multirow{4}{*}{$\begin{array}{c}17-18 \\
\text { (A) }\end{array}$} & 2 & 1,00 & 0,90 & 0,99 & $-0,19$ & 0,94 & 0,08 & 0,99 & 0,94 & 0,96 & 0,50 & $-0,65$ & 0,40 \\
\hline & 3 & 0,90 & 1,00 & 0,94 & $-0,59$ & 0,71 & $-0,35$ & 0,84 & 0,71 & 0,74 & 0,08 & $-0,91$ & $-0,03$ \\
\hline & 4 & 0,99 & 0,94 & 1,00 & $-0,29$ & 0,91 & $-0,02$ & 0,97 & 0,91 & 0,92 & 0,41 & $-0,73$ & 0,30 \\
\hline & 5 & $-0,19$ & $-0,59$ & $-0,29$ & 1,00 & 0,14 & 0,96 & $-0,06$ & 0,14 & 0,11 & 0,76 & 0,87 & 0,83 \\
\hline \multirow{4}{*}{$\begin{array}{c}19-20 \\
\text { (B) }\end{array}$} & 2 & 0,94 & 0,71 & 0,91 & 0,14 & 1,00 & 0,40 & 0,98 & 1,00 & 1,00 & 0,76 & $-0,37$ & 0,68 \\
\hline & 3 & 0,08 & $-0,35$ & $-0,02$ & 0,96 & 0,40 & 1,00 & 0,21 & 0,40 & 0,37 & 0,90 & 0,70 & 0,95 \\
\hline & 4 & 0,99 & 0,84 & 0,97 & $-0,06$ & 0,98 & 0,21 & 1,00 & 0,98 & 0,99 & 0,61 & $-0,55$ & 0,52 \\
\hline & 5 & 0,94 & 0,71 & 0,91 & 0,14 & 1,00 & 0,40 & 0,98 & 1,00 & 1,00 & 0,76 & $-0,37$ & 0,68 \\
\hline \multirow{4}{*}{$\begin{array}{c}21-22 \\
\text { (C) }\end{array}$} & 2 & 0,96 & 0,74 & 0,92 & 0,11 & 1,00 & 0,37 & 0,99 & 1,00 & 1,00 & 0,73 & $-0,41$ & 0,65 \\
\hline & 3 & 0,50 & 0,08 & 0,41 & 0,76 & 0,76 & 0,90 & 0,61 & 0,76 & 0,73 & 1,00 & 0,33 & 0,99 \\
\hline & 4 & $-0,65$ & $-0,91$ & $-0,73$ & 0,87 & $-0,37$ & 0,70 & $-0,55$ & $-0,37$ & $-0,41$ & 0,33 & 1,00 & 0,43 \\
\hline & 5 & 0,40 & $-0,03$ & 0,30 & 0,83 & 0,68 & 0,95 & 0,52 & 0,68 & 0,65 & 0,99 & 0,43 & 1,00 \\
\hline
\end{tabular}

Here the classical formula was used. However, we decided to use it in a nonstandard way. The whole obtained correlation coefficients were divided into separate quadrants and assigned each a binary letter code. Each focus group was coded by single letter code:

the group of 17-18 years old - A; the group of 19-20 years old - B; the group of 21-22 years old - C.

Based on Table 1, it is evident that there is a robust correlation $(0,9-0,99)$ inside each quadrant ( $\mathrm{AA}, \mathrm{BB}$ and $\mathrm{CC}$ ), which tells us that there are very tight connections between the answers of each separate focus group. Also, it gives us all rights to believe that formulated questionary was correct and representative.

At the same time, we can notice that only two quadrants are very important to be analyzed:

- $\quad \mathbf{A B}$ quadrant, which is the interconnection between answers of the 1st and 3rd-year students. Taking into account robust correlation between the majority of indicators (from 0,71 to 0,99 in the majority), we can conclude that communicational problems of students teaching in these groups are very likely;

- $\quad$ BC quadrant, which characterizes the quality of connections between the answers of the 3rd and 5 th year students. We see that a strong correlation between the answers still exists. However, such correlation is comparatively lower than at $A B$ quadrant. That describes us that the communicational problems gradually decline - but only up to higher courses and even graduation.

Nevertheless, we must explain a correlation inside of the other quadrants that we separated:

- AC quadrant, which is the interconnection between answers of the 1st and 5th-year students. We see that correlation is primarily weak and very weak (less than 0,60 ). At the same time, 
some of the massives show us a robust negative correlation, which reflects the opposite connection. We shall not take it into account.

- CC quadrant, which shows us a correlation inside the quadrant itself. The quality of connections is primarily poor. We have concluded that students of this age are worried about another problem: personal, professional success, development of additional skills, getting off a good job, creating a family.

It should also be noted that the COVID-19 pandemic causes the current situation in higher education. Due to numerous quarantine restrictions in many countries, universities are forced to switch to online education. Unfortunately, online education (with all its advantages) does not allow students to communicate fully. It, in turn, exacerbates young people's urge to communicate online, which was a big problem before the pandemic. Here are some facts [10]:

- Instagram social network today has 1.15 billion active users;

- More than half of all active Instagram users today are under 34;

- The most significant part of active users from this group are young people aged 18-24. Students!

It means that more and more of them are choosing to communicate online over social networks using pictures, short videos and, in some cases, short messages. Abuse of such communication also leads to a loss of communication skills of personal communication.

Moreover, this, in our opinion, is another circumstance that hinders the students' integration into their society (we are not even talking about inclusion here).

Based on the survey, its analysis, and our deductive logical conclusions, it is possible to distinguish four fundamental problems of modern higher education from an inclusive position (Figure 2).

From this point of view (Based on Figure 2), inclusive higher education should be considered a fundamental factor in the socio-cultural development of the individual and society as a whole. In this aspect, society should be understood as a human community, which will be the basis of economic, social, and cultural transformations in the future (in 10-20 years).

Figure 2. The fundamental problems of higher education from the inclusion position that we have distinguished after performed research (Authors research)

Fundamental problems distinguished on logic and correlational analysis

1. Mostly, all students admitted to the universities have communicational problems with their peers - groupmates.

2. This statement is true even despite whether the student needed special learning conditions or not before entering the university.

3. The inclusiveness of higher education must be guaranteed to every student. However, not everyone needs it.

4. The inclusiveness of higher education must start from the period of integration. It means that mentally, communicatively, socially, different people should be able to enter a single society smoothly. It is generally not customary to talk about integration in higher education.

In addition, this human community will give a start to the next generations.

Thus, by improving higher education in true inclusiveness, we are already laying the foundation for human relations and well-being for the next 40-60 years.

That is why we have paid particular attention to the socio-cultural role of inclusive higher education. 
If, as a result of the incorrect organization of inclusive education process, after graduation from the university, we will obtain thousands of young people for whom it is not very easy to communicate with their peers, partners - the same age and others. It will be educated persons, closed in themselves, who will find it difficult not only to create communities but also to integrate into them.

The problem is aggravated by the fact that nowadays, it does not matter whether the student had special educational needs before admission or not. Every student now needs a unique learning environment.

What do we see as the prospects for the development of inclusive higher education?

First of all, the organizers of the educational process (university administration; employees of dean's offices; teaching staff) should be aware of what inclusive higher education today is and at whom it should be directed. For this purpose, it is necessary to conduct training on psychological literacy for all employees admitted to working with students.

Secondly, to conduct periodic psychological monitoring of people directly involved in teaching and giving final marks. It is necessary to understand whether the teacher is aware of the full responsibility for the incorrect treatment of students.

Thirdly, it is necessary to introduce into the staff of the departments a teacher-practicing psychologist who would replace the classical curators (or supplement their work). His/her main task will be to create psychological portraits of students, assess the quality of the communicative environment in students' society, and identify and resolve possible conflicts (misunderstanding, bullying and others). These portraits will be helpful for teachers who are just starting to work with a new group of students and who are not professional psychologists.

Fourth, it is necessary to encourage teachers to pay more attention to the student's personality. For this purpose, the teacher can create thematic groups in social networks to conduct his work with students. The ultimate goal of this activity should be bringing students to personal communication by increasing their interest in the work of the teacher, the life of the department and others.

Fifth, the psychological service and staff of the dean's office should identify those students who do not have communication problems in their communities and encourage them to address inclusiveness issues.

Sixth, postgraduate students - future teachers must necessarily study the basics of modern inclusive education and have at least fundamental knowledge about target groups' psychology and psychological problems - students aged 17-22.

Ultimately, this is the most fundamental perhaps. Universities should create a particular infrastructure and organize the educational process in such a way that first-year students have the opportunity to smoothly and gradually integrate into the new society (in particular, by introducing all the previous points). Such a particular organization of the educational process should be carried out at least during the first semester.

Indeed, these problems of organizing the educational process within inclusive education are not the only ones. Today's reality shows that still in many countries, many universities are characterized by the absence of:

- $\quad$ sufficient funding of inclusive education projects;

- enough experience in the sphere of inclusive education;

- trained human resources to work with student of different educational needs;

- often, unfortunately, there is no even a desire to delve into the problems of students that are not directly related to the educational process.

Each of the points listed is a particular scientific and practical problem. Separate future scientific works will be devoted to the study of each of them. 
At the same time, we can conclude that the problem of inclusive university education exists even nowadays. Furthermore, this method of organizing the educational process should not be left to chance but be the basis for severe scientific discussions.

\section{Conclusions prospects for further research.}

In this regard, we can conclude that universities are facing serious challenges today. Modern higher education cannot be limited exclusively to teaching, methodological, scientific work. Nowadays, the university is an association of people - personalities, each of which has its own mental, social, cultural characteristics.

It means that the main task of the organizers of the educational process at universities is not only to provide students with the highest quality of education, but also to promote socialization, communication between students; preventing the aggravation of social conflicts (on different soils); creation of all possible conditions for effective personal development.

In the context of numerous distance courses, it is especially true now, forcedly organized by universities caused by the coronavirus pandemic and the high popularity of social networks and telecommunication technologies among young people.

However, it is not only the administration and teachers who have to create this environment. Students themselves should be involved in this kind of activity. It is necessary to encourage their communication, the joint spending of free time, the involvement in this communication of people who do not want to be in society, and students with special educational needs.

It is necessary to stimulate the activity, purposefulness and ambition of students, regardless of whether they have special educational needs or not. Students who simply find it hard to communicate or have no motivation for this (interest, perhaps) should also be considered as participators of inclusive education.

It is time to realize that with the help of the correct organization of inclusive education in higher education, today's desires and ambitions will turn into tomorrow's accomplishments.

\section{References}

1. Bondar, I., Bachynska, N., Novalska, T., Kasian, V., Kuchnarov, V., Pylypiv, V. (2020). Analysis of the organization and features of the implementation of information technologies in the educational process of institutions of higher education. Systematic Reviews in Pharmacy, 11(11), pp. 868-872.

2. Bondar, I., Humeniuk, T., Batchenko, L., Horban, Y., Honchar, L. (2021). State Regulation of the Development of Educational and Scientific Process in Higher Education Institutions. Journal of Management Information and Decision Science, 24(2), pp. 1-10.

3. Gumenyuk, T., Palchynska, M., Herchanivska, P., Kozak, Y., Kobyzhcha, N. (2021). Overcoming the modern socio-cultural crisis - From postmodern to post-postmodern: Theoretical aspects. International Journal of Criminology and Sociology, 10(8), pp. 745-752.

4. Bondar, I., Gumenyuk, T., Horban, Y., Karakoz, O., Chaikovska, O. (2021). Distance E-learning in the system of professional development of corporation managers: Challenges of COVID-19. Journal of Education and e-Learning Research, 7(4), pp. 456-463.

5. Bondar, I., Humenchuk, A., Horban, Y., Honchar, L., Koshelieva, O. (2021). Conceptual and Innovative Approaches of Higher Education Institutions (Heis) to the Model of Training A Successful Specialist Formation During a Covid Pandemic. Journal of Management Information and Decision Sciences, 24(3), pp. 1-8.

6. Avramidis, E., Norwich, B. (2002). Teachers' attitudes towards integration/inclusion: A review of the literature. European Journal of Special Needs Education, 17(2), pp. 129-147. 
7. Archer, L., Hutchings, M., Ross, A., Leathwood, C., Gilchrist, R., Phillips, D. (2005). Higher education and social class: Issues of exclusion and inclusion. Higher Education and Social Class: Issues of Exclusion and Inclusion, pp. 1-227.

8. Fuller, M., Bradley, A., Healey, M. (2004). Incorporating disabled students within an inclusive higher education environment. Disability and Society, 19(5), pp. 455-468.

9. Pearson Correlations - Quick Introduction - https://www.spss-tutorials.com/pearson-correlationcoefficient/

10.367 Social Media Statistics You Must Know In 2021 -

https://www.socialpilot.co/blog/social-media-statistics\#insta-usage-stats 